\title{
Article
}

\section{Transparency of Assessment in Practice Education: the TAPE Model}

Stone, Clare

Available at http://clok.uclan.ac.uk/22695/

Stone, Clare ORCID: 0000-0001-7331-4244 (2018) Transparency of Assessment in Practice Education: the TAPE Model. Social Work Education, 37 (8). pp. 977-994. ISSN 0261-5479

It is advisable to refer to the publisher's version if you intend to cite from the work. http://dx.doi.org/10.1080/02615479.2018.1475556

For more information about UCLan's research in this area go to http://www.uclan.ac.uk/researchgroups/ and search for < name of research Group>.

For information about Research generally at UCLan please go to http://www.uclan.ac.uk/research/

All outputs in CLoK are protected by Intellectual Property Rights law, including Copyright law. Copyright, IPR and Moral Rights for the works on this site are retained by the individual authors and/or other copyright owners. Terms and conditions for use of this material are defined in the policies page.

\section{CLoK}

Central Lancashire online Knowledge www.clok.uclan.ac.uk

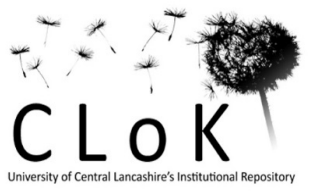




\title{
Transparency of Assessment in Practice Education: the TAPE Model
}

\begin{abstract}
This article draws upon empirical research which explored how undergraduate and postgraduate social work students, at one university in England, experienced working alongside practice educators. In-depth interviews with eight participants enabled them to explore their placement experiences and in relation to assessment, social work students predominantly focused on the direct observations of their practice and written work. The findings suggest that students were less clear about the range of assessment methods employed and how stakeholders contribute towards formative and summative assessment. This article presents the Transparency of Assessment in Practice Education: the TAPE Model, which is designed to make the elements of assessment explicit. This model outlines six Ws which comprise the measurement of assessment. It is suitable to use with social work students, newly qualified social workers undertaking their Assessed and Supported Year in Employment, and can bring transparency to other assessment situations in the workplace or classroom.
\end{abstract}

\section{Abstract word count 149}

Key words; Assessment, practice educators, practice learning, social work students, phenomenology.

$==$

Declaration: this manuscript has not been published elsewhere and has not been submitted simultaneously for publication elsewhere. There are no disclosures or conflict of interests to note.

\section{Article word count excluding reference list $=7437$}




\section{Introduction}

In England, the current social work degree programmes are shaped by standards and requirements drawn up by The College of Social Work (TCSW), The Quality Assurance Agency (QAA), and The Health and Care Professions Council (HCPC). Although The College of Social Work is no longer in existence, their standards are currently still used. A new professional body called Social Work England will take over the registration of social workers from the HCPC and it is expected they will introduce new educational standards. At the time of writing, little is publicly known about the changes Social Work England will introduce, including any amendments to practice learning requirements and assessment.

In England, practice educators are social work practitioners who supervise, teach and assess social work students on practice learning placements and make a recommendation to the awarding institution whether a student is 'fit to practise at the point of qualification' (Social Work Reform Board. SWRB, 2010a:1). In partnership with the awarding university, the practice educator is situated as important in education, training and 'gatekeeping' for the social work profession (Bogo, Regehr, Hughes, Power, \& Gioberman, 2002; Miller \& Koerin, 2001). Outside of the UK, the terms 'field educator' or 'field instructor' are frequently used to refer to the role of the practice educator and 'field education' is used to describe the practice learning placement or opportunity.

Both undergraduate and postgraduate social work students in England undertake two practice learning placements; the first for 70 days and, in their final year, a longer one of 100 days (TCSW, 2013). Each student is appointed a practice educator who is responsible for ensuring appropriate learning opportunities are made available to the student. The practice educator also teaches the student, supervises them and oversees the assessment of their competence and capability. 
Some students also have a practice supervisor who manages the student's practice on a day-to-day basis and this is common where the practice educator is not employed within the team or by the agency where the placement is being hosted. This model is commonly employed within third sector agencies and the practice educator is referred to as 'offsite'. The Practice Educator Professional Standards (PEPS) were developed by The Social Work Reform Board (SWRB) and are now hosted by The British Association of Social Workers (BASW) (SWRB, 2010b). The PEPS offer guidance to universities in relation to the experiences and qualifications required to be a practice educator.

Common structures to practice learning placements include the drawing up of a learning agreement, midpoint review and final review and it is usual practice for the university tutor to have active involvement in these activities (Thompson, 2006). The practice educator is asked to formally observe the student engaging with service users and assess against the Professional Capabilities Framework (PCF) and the Standards of Proficiency (SOP) (BASW, 2016; HCPC, 2012). Although the practice educator is responsible for co-ordinating the learning opportunities, supporting and assessing the student, they do not undertake these tasks in isolation. Indeed, the views of others are considered important and it is advocated that feedback ought to be obtained from service users, carers, other professionals within their own service and practitioners from other agencies (Doel, 2010; Mathews, Simpson, \& Crawford, 2014; Nicholas \& Kerr, 2015). It is advisable to obtain feedback from these stakeholders throughout the duration of the placement and it is recognised as good practice to do this more formally at the midpoint of placement. This is because formative assessment enables the student to know how well they are progressing and to identify developmental needs. The student and practice educator can develop a learning plan, for the remainder of the placement, to shape the learning opportunities and respond to the student's support needs. The summative assessment occurs at the end of the 
placement where the practice educator draws upon a range of evidence to make a recommendation about whether the student has passed the placement and it is imperative that a range of perspectives are represented within this summative judgement.

Although the practice educator is responsible for overseeing the supervision, teaching and assessment of social work students (TCSW, 2012b), how they carry out these tasks has received little research attention. Existing research into social work practice education is rather limited but includes for example the use of assessment frameworks (Stone, 2014b) and the use of performance measures to assess outcomes in student learning and assessment (Cleak, Hawkins, Williams, \& Laughton, 2015). The important role practice educators can play in initial social work education has been explored (Stone, 2016) and also the reasons why they may be reluctant to fail students (Finch, 2009; Finch \& Parker, 2013; Finch \& Taylor, 2012). Research has considered the relationship between supervision quality and student satisfaction (Kanno \& Koeske, 2010); relationships between students and practice educators (Lefevre, 2005; Zeira \& Schiff, 2014); and attention has been drawn to strategies practice educators may employ to reduce anxiety in students (Baird, 2016).

Despite the growing body of knowledge about practice education, there is little contemporary empirical research into how students actually experience working alongside a practice educator and especially how they perceive assessment during the practice learning placement; therefore this study set out to generate new knowledge by capturing the voices of social work students.

\section{Method}

Phenomenological research focuses attention onto a phenomenon 'to illuminate' 
it through the perspectives of relevant 'actors' (Lester, 1999:1). Phenomenological methodology is therefore relevant because the aim of this research was to explore how assessment (the phenomenon) is experienced by social work students (the actors). Interpretative Phenomenological Analysis (IPA) is particularly relevant because it focuses on the participants' perspectives of the phenomenon rather than aiming to produce a detailed 'description of what participants actually do in practice' (Stone, 2015:12). Therefore, the interpreting process within IPA (Smith, 1996) is more relevant, than traditional descriptive phenomenology, to the topic being researched (Dahlberg, 2006; Pringle, Drummond, McLafferty, \& Hendry, 2011) because the aim was to generate insights into social work students' perspectives rather than describe assessment. IPA takes into account a range of individual perspectives and therefore, in this context, did not seek to produce an objective statement about how all social work students experience working alongside a practice educator and assessment by them (Giorgi \& Giorgi, 2008; Smith \& Osborn, 2008).

Semi-structured interviews were designed to offer the opportunity for participants to speak about their unique experiences of the practice educators' role in supervision, teaching and assessment. Rich data can be generated when the participant takes a greater degree of control during the interview to the point where they may share experiences and insights into the phenomenon that the researcher may not have previously considered. Rather than asking a set of questions in the same order, cards were laid out in front of each participant in a random manner to ensure no hierarchical significance. Each card included the beginning of a sentence to focus attention onto a topic related to working alongside a practice educator. This was designed to empower the research participants to speak about matters of importance to them. They were invited to select any of the cards they wished to speak about, they chose the order and were advised that it did not matter how few or how many of the cards they addressed 
during the interview. The participants were reminded that the focus of the interview was their experiences of working alongside a practice educator and there were no right or wrong topics or answers.

Using the cards in this way enabled participants to share their perspectives and talk about aspects that were meaningful for themselves. Spontaneous probe questions were also used to obtain further detail and clarity to ensure their perspectives had been understood (Lodico, Spaulding, \& Voegtle, 2010).

The cards became a visual stimuli and all but one participant moved the cards around and picked them up. One participant began to talk about their experience of the practice educator and did not refer to the cards at all. As an academic working in the higher educational establishment where the participants were students, the researcher was aware of potential power dynamics at play. Offering participants the opportunity to select cards (or not) and thereby enabling them to influence the direction of the interview, felt respectful and worked towards redressing power imbalances and facilitated a more collegial experience.

The seven cards displayed on a table at the outset of the interview:

- My experiences of being supervised by a practice educator....

- My experiences of being assessed by a practice educator....

- My experiences of being taught by a practice educator....

- My experiences of the teaching and learning relationship on placement are ....

- If I were a practice educator I would ensure ....

- The practice educator was a good / poor role model because....

- I felt valued / respected by the practice educator....

Final year social work students within the School of Social Work, Care and Community at the University of Central Lancashire who had experience of working alongside two practice educators were invited by email to take part. This 
purposive sampling technique (Creswell, 1998) was employed to ensure the participants had 'particular life experience' (Vandermause \& Fleming, 2011:372) relevant to the research question. Students undertaking the Masters Award in Social Work (MA) have a placement in year one and year two, and those undertaking the Degree level award (BA) complete a placement in year two and undertake the final placement in year three. Due to the timing of the interviews, some MA students were nearing the end of their final placement whereas all of the BA students had completed all of their placement days. A total of eight social work students volunteered to take part in the research and this number is conducive for IPA (Lester, 1999; Smith \& Osborn, 2008): as Lester advises 'a single-figure sample is valid' in phenomenological research (Lester, 1999:3).

Five of the students were female and three male, and all within the age range of 20 to 49. Five were from the MA programme and three from the BA. During their first placements, only two of the participants had onsite practice educators but all eight participants had onsite practice educators during the final placement: therefore six of the students had the experience of working alongside both onsite and offsite practice educators. Their placement settings included young people's services (3), older adults (2), homelessness services (2), children and families (5), adult services (3) and a domestic violence agency (1).

As an insider researcher, ethical considerations including power and potential impact upon the students were paramount for me (Hockey, 1993). Because I was involved in teaching undergraduate students, the email inviting them to volunteer for interview was sent after they had received their final academic assessment grades and module feedback to ensure they did not associate the research with their assessment or attainment. Timing the invitation in this way was essential to avoid students feeling under duress or 'feel obliged to co-operate' (Costley, Elliott, \& Gibbs, 2010:3). The research received ethical approval from The 
University of Central Lancashire and all participants received an information sheet and signed a consent form. They were advised that they had the right to withdraw up to one week after the interview had taken place. Students were invited to choose a participant pseudonym, however it should be noted that two participants chose the same name and post interview the researcher selected a different name for one of the participants.

The author of this article facilitated the interviews, each lasted for the duration of around one hour and all were audio recorded. A transcriber was commissioned and the researcher undertook thematic analysis based on IPA principles (Smith, Jarman, \& Osborn, 1999; Smith \& Osborn, 2008; Stone, 2015). NVivo was primarily used as a data management tool.

\section{Findings}

Whilst the research participants spoke about a wide range of topics in relation to working alongside a practice educator, due to the depth of data and the criticality of discussion warranted, this article focuses only upon their experiences of assessment. All names included here are pseudonyms.

\section{Assessment by direct observations and written work}

When considering assessment on placement Louise, like other participants, immediately mentioned direct observations:

"Well I've had three observations so far, with a fourth one next week". (Louise)

When prompted to reflect on his experiences of being assessed, Ovor asked: 
“Are you talking in terms of observation?" (Ovor)

Anne spoke about her initial anxieties of the direct observations and when asked "how else were you assessed?" Anne replied:

"I guess just through the work that I produced and my reflections and everything like that. Because that was quite a big part, because being a reflective person anyway, most of my efforts went into writing new reflections at the end of the night and writing them up and emailing them every week". (Anne)

When asked "were you aware that you were being assessed", Stacey immediately said "yes":

“it's common sense to me that you're going to be assessed on your placement". (Stacey)

However, like other participants, Stacey only spoke about written work and direct observations of her practice. Louise had an off-site practice educator during her first placement and, when asked how he assessed her, she replied:

"I don't think he did really because he was never there in the background on a day when it wasn't a formal observation. It was purely those, he was in, watched and then gone again. So he wouldn't have seen anything else, apart from the set up ones." (Louise)

Louise was not aware that she was being assessed during supervision sessions nor was she aware that others in the workplace may have been assessing her. She makes the point that the staff team on placement saw her engage with young people all of the time but as they did not write notes, Louise did not consider this to be part of the assessment: 
"But they would observe my interactions as a whole really because they were always with me, but they never did a write up as such I don't think". (Louise)

John had mentioned assessment by direct observations and written work and when asked "are they the only ways you've been assessed", he began to reflect back on his experience and after thought he replied:

“I think I've probably been assessed informally....Yes, that's where he's sort of like assessing like a ninja ... like a hidden assessment ..." (John)

He went on to explain:

"Yes, because, well it's hidden in the respect of the student doesn't really know they're being assessed but they are being assessed all the time. ...Yes, it's only when I've got into year two that I'm thinking about that" (John)

During the interview, John began to see that assessment extended beyond formal observations of his practice and his written work. His use of the term 'hidden assessment' appropriately captures the experiences of the participants in this research. The extent and range of assessment was not fully obvious to them when they were on placement.

\section{Feedback from others}

Some participants appeared to understand feedback mechanisms, however others reported that the practice educator undertook their assessment decisions alone (even when they were an off-site practice educator). When they started the placement, some students did not appear to understand that others had a role in 
the formative and summative aspects of the placement.

Farida was surprised during her first placement when the off-site practice educator told her positive things that others in the placement setting had said about her:

"So I didn't realise until they were coming back to feedback to me, to say that such a body said this, such a body said that. Like they must have had meetings" (Farida)

Farida had not anticipated that people other than her practice educator would be assessing her capabilities. Here she explains that following a joint home visit, a female social worker contacted the practice educator to discuss Farida's performance:

"the person who interviewed [the service user] had already rang back to the office and gave my feedback. ... I was constantly being observed but I didn't realise it was being done" (Farida)

John was so nervous about the arranged observations he claims "I used to nearly hyperventilate at the time I had an observation." However this anxiety did not transfer to day to day practice as he was unaware that he was being assessed. John recounted his experience of going to a meeting with the Chief Executive and was not anxious about practicing in front of someone of this status because:

"I wasn't aware that I was being assessed for it ... to be honest with you, because I think if I'd known about it, I think there would have been potential for me to get worried and stuff and think, oh well what happens if I mix up my knowledge and stuff and then I don't achieve that, and all that sort of stuff? So I did think it was helpful to do it without me knowing." (John) 
John did not appear to consider the need to impress those within the placement agency and may only have attributed value to this had he been aware that observations by others would be formally fed back to the practice educator.

\section{Surveillance and monitoring}

When asked if she was "aware of being assessed around the office" Stacey replied that the social workers in the team were "weighing" her up as a person in the "first week" but she did not consider this to form part of her placement assessment. Stacey did not appear to have a good relationship with her practice educator and constructed the ongoing watching by the practice educator as negative surveillance. She explained how the direct observation of practice made her nervous because the practice educator is "watching your every move" (Stacey).

Other participants also spoke of continuous watching in negative terms. It appeared that they considered that being continually observed was unreasonable and not a required part of practice learning assessment. Anne was aware that people in the office were watching her but phrased it to suggest that this was for the purposes of management and to ensure she was doing things correctly rather than it being an accepted practice when assessing students:

"I guess you know you're being listened to and overheard, ... if you say something slightly out of line, someone will give you a funny look or, you know, was that quite right?" (Anne)

Although she appeared to understand how those around her would pay attention to her practice in terms of quality assurance (for example to protect service users), Anne had less insight into how the assessment processes related to her professional development as a social work student. 
Shannon disliked the close proximity to the practice educator in the office. She described feeling that the practice educator was monitoring her and listened to her telephone conversations and when asked "were you aware when you were being assessed?" she replied:

\footnotetext{
"Yes, it was constant with my practice educator. She was listening to everything that I did and always keeping one eye on me. ... if I were making the phone calls, she was always listening. So she was on the ball, watching what I was doing and everything, and listening all the time. She could listen while she was typing and stuff like that."
}

(Shannon)

The students who did not appear to have a good relationship with their practice educator adopted a negative view of ongoing monitoring and surveillance: they felt that they were watched to see whether they slipped up, rather than seeing it as a means of informing constructive feedback. Whilst aware of the practice educators' observation of them, they did not necessarily associate this with what may be considered reasonable ongoing continuous assessment which is expected within the teaching, supervision and assessment of social work students.

\section{Trust and Autonomy}

Shannon did not speak favourably about her final placement practice educator and constructed a picture of constant vigilance undertaken in order that the educator could point out when she did things wrong. This experience can be contrasted with that of her first placement, in relation to which she spoke favourably about the practice educator and practice supervisor, and perceived that she was left to get on with tasks autonomously because she was trusted. Asked if she was aware of the practice supervisor in the first placement assessing her, Shannon was under the impression that he was monitoring other staff but not her 
because she could be trusted:

"I think he always had one ear open on what all the other staff were doing, but there was a lot of issues going on in the organisation. So I think he was more concerned about what the staff were doing than what I was doing, to be honest. I think he quite respected me really because he knew that he could trust me. Whereas, the staff were a bit iffy." (Shannon)

Shannon considered that assessment took place when she was in direct view of her practice educator:

"I went to do a multi-agency meeting that [the practice educator] was meant to come to and then she couldn't come. I went on my own and I felt like, oh my god, but it went really well actually, so I definitely wasn't being assessed about that. ... And then I was asked to work with another social worker, like on her case, a little boy ... And I did that all autonomously, I got all the resources by myself, planned all the sessions myself and did it all, and no one assessed me at all on that, they just let me do it." (Shannon)

It is reasonable to assume that those allocating the work to Shannon will have made an informed judgement of her capability, confidence and competence to consider that she was ready to attend meetings alone and do direct work with children. This is perhaps the trust that Shannon spoke about (she was trusted to get on with tasks) yet it would appear that she thought she was not assessed because she was working independently and out of sight.

\section{The final report}

Those students who did receive feedback during the placement spoke in very 
positive terms about its value but unfortunately not all students appeared to receive ongoing developmental feedback with some being unsure as to what would be within the final report. Although Farida was nearing the end of her placement, she stated that she did not know how well she was doing despite having supervision and a mid-point review meeting. Farida appeared to have a good relationship with her offsite practice educator and the staff team in the first placement but did not have the similarly positive relationships in her final placement. Farida was a few days from the end of her placement at the time of interview and was anxious to know what would be in the final report:

“And it's making me a bit anxious for my final report, when I get it back off her, to see what she's put in it .... So yes, like I just dread the final report, to see what she puts in it" (Farida)

Although John had spoken about being receptive to feedback, he too lacked knowledge about how well he was progressing on placement and was unsure whether he was going to be awarded a pass for his placement:

"I probably won't know what the outcome of that will be until the final report" (John)

\section{Discussion}

The analysis of data suggests that those students participating in this study had different assessment experiences during their practice learning placements. They understood that assessment was taking place when the practice educator looked at their written work, which included agency documentation and portfolio work, and undertook direct observations of their practice. Direct observations are prearranged opportunities for the practice educator to observe the student's 
practice and setting these events up will usually involve making the reason for the practice educator's presence transparent. The participants had less appreciation that the practice educator would draw upon a wider range of evidence and obtain feedback from different people: this included the practice supervisor with whom the student worked alongside on a daily basis. Although some students spoke about the benefits of feedback, not all students appeared to have received adequate levels of formative feedback and some had to wait until the final report to learn how well they had done and whether they had passed the placement.

Although Parker (2010) cautions that 'students must know what is to be assessed and how it will be evaluated' not all students who participated in this research appeared to have such awareness (Parker, 2010a:102). Therefore even if the university and the practice educator consider they have informed students about assessment during practice placements, the findings in this research suggest that students do need more clarity in relation to:

- who assesses them,

- when they are being assessed,

- where assessment is taking place,

- the way they are assessed and

- what activities other than performance and writing are being assessed.

Lack of clarity and transparency in relation to the six Ws of assessment (who, when, why, where, way and what) may contribute to students' uncertainty on placement and exacerbate relationship problems with the practice educator. Many of the participants in this research spoke about their relationship with the practice educator and there does appear to be a link between the relationship and how they experienced assessment. Those students who spoke more 
favourably about their practice educator presented as less anxious (other than performance anxiety during direct observations) to the extent that they did not appear to realise they were being continually assessed. Those students who did not appear to enjoy working alongside their practice educator spoke in ways that suggested they had negative feelings and perceptions about being continually monitored and watched over (rather than appropriately assessed). It is not possible within the context of this research to explore the causal relationship further, but it is pertinent to question this chicken and egg scenario. Further exploration may offer insight into whether the students' perception of the relationship develops first and this influences their experiences of assessment, or whether it is the other way round.

Lefevre (2005) also found the relationship with the supervisor to be significant in terms of how the student experienced assessment with those students who considered the relationship to be supportive more likely to perceive their assessment to be more accurate and fair (Lefevre, 2005). Lefevre uses the phrase 'collaborative and transparent in the assessment' and states:

The presence of an appropriately supportive environment also meant respondents believed they were more likely to receive, accept and use critical feedback to develop their practice. This would then, in turn, be observed and assessed by the practice [educator], leading to more useful critical feedback. Given that evidence of competence is collected throughout the placement, this suggested the existence of an ongoing constructive looping process between formative and summative assessment, maximizing learning opportunities. (Lefevre, 2005:576)

The participants in the Lefevre study appear to benefit more from ongoing formative assessment and feedback than did the participants in this current research. However, there was similarity in relation to the significance that students placed on the quality of the relationship within education and their training. The participants in this research regarded the practice educator as having ownership of power and control in the relationship: this is not the collaborative and transparent relationship advocated by Lefevre. John, one of the participants 
in this research, described the practice educator as a 'Ninja' characterising them as going about their business with 'stealthy movement and camouflage' (O.E.D., 2015:983). Therefore, making the elements of assessment more transparent and explicit may help to remove such camouflage and the students may experience the practice educator's role as less furtive. Transparency has the potential to help in the development of a more trusting and productive relationship within the placement setting.

It is a requirement in England that before a student commences placement their readiness for direct practice is assessed (BASW, 2016; SWRB, 2010a). As part of preparing students for placement, it would be expected that the principles of learning, development and assessment would be outlined by the university and guidance provided in a practice-learning handbook. Although appropriate information may be available prior to the placement starting, it is possible that it will not be assimilated or retained by students at that point in time. Returning to the principles of assessment during the practice learning experience could serve as a useful reminder.

Traditionally, at the outset of the placement, a learning agreement is drawn up between the placement agency, student and university and is revisited during the placement (Thompson, 2006). At the mid and end points of placement, review meetings take place and assessment documentation is completed. As these are important stages in the placement, the university tutor will usually attend to help appraise progress and ensure that the student's needs are met. Despite the significance of these events, the tutors' involvement in such meetings did not appear to have impact or relevance in relation to how the students experienced assessment on placement. Although students receive comprehensive information before commencing placement, it is possible that some may not understand the many dimensions of assessment, forget or they may put it to the back of their minds. There are many opportunities to reinforce messages about assessment 
within the placement documentation and in the meetings that take place either at the university or within the placement setting. The agendas and proformas for preplacement meeting, learning agreement, supervision sessions, mid placement review and final review meetings could potentially include further guidance about the six Ws of assessment.

\section{Who is involved in assessment during practice learning placements?}

Since the introduction of the Professional Capabilities Framework in 2013, consideration has been given to the nature of holistic assessment and how students need to demonstrate competence and capability across the range of professional domains (Field, Littler, \& Jasper, 2014; Stone, 2014a; TCSW, 2012a). However, an often overlooked dimension of holistic assessment is the use of feedback and evidence from a range of stakeholders. The judgement and views of others certainly appeared to have been overlooked by students participating in this research because they were surprised that the offsite practice educator had spoken to the placement supervisor and that other professionals provided feedback on their performance. All students need to be made aware that everyone they encounter may be asked for 'testimonial evidence' and their views can contribute towards the assessment of competence and capability (Maclean \& Caffrey, 2014:82). Parker (2004) advises students that 'the views and opinions of people you work with is crucial evidence in identifying your learning needs and assessing competence' (Parker, 2004:90). For a student social worker, every action, interaction, behaviour, written and spoken word to anyone and everyone can matter. It is good practice for the student to understand who is involved in their assessment and how their voices will be captured and represented within assessment. 


\section{When assessment occurs}

Assessment commences from the very first contact with the placement which may be an application form, student profile or a preplacement visit. This is the point at which practice educators 'begin to form an assessment of the particular student's needs' and establish whether a suitable learning opportunity could be offered to meet their individual needs (Field et al., 2014:29).

Although students situated the final report as the most important element of assessment (because it records the judgement as to whether they have passed the placement) assessment activity takes place throughout the entire practice learning period. There are staging posts built into the placement which are formative points of assessment and these include for example supervision, mid-point reviews and observations of practice. These points within the placement create opportunity for the student to receive feedback on their progress and have support to act upon it (Thompson, 2006).

\section{Why students are assessed}

Diagnostic assessment occurs early in the placement to help in the identification of learning needs and the educational provision required to meet that need (Beverley \& Worsley, 2007). The next type of assessment is formative and this is intended to judge progress so that the student can be given feedback and the educator can shape and improve learning opportunities and teaching. The end point assessment is called summative and this identifies 'how well students have learned what they were supposed to have learned' (Biggs \& Tang, 2007). Summative assessment is contained in the practice educator's report and it is their recommendation as to whether the social work student has passed the placement. Students need to understand and be aware "whether assessment is formative or 
summative' in order that they are afforded a safe and nurturing environment to develop, grow and learn (Williams \& Rutter, 2010:102). Some of the participants illustrated how their practice educators used assessment to support development, however there were other students who apparently had to wait until the final report was produced to learn how well they had done:

The student should not be surprised at the contents of the mid- or final assessment reports, as practice educators should provide the student with constant, formative feedback. (Finch, 2017:78)

Students ought to be afforded the opportunity to receive and discuss feedback throughout the placement but they may need support to understand and use

feedback productively (Ketner, VanCleave, \& Cooper-Bolinskey, 2017). The practice educator has an important role here to ensure that the student understands why they are being assessed. They also have a responsibility to celebrate strengths and achievements, and to support the student to address areas for development in order that they can be given the best opportunity to succeed.

\section{Where assessment takes place}

The student participants in this research appeared to understand that assessment occurs in settings occupied by service users and in offices. The data gives rise to question the extent and range of understanding that assessment can take place in every space that the student inhibits: whether it be physical or virtual, social or professional. Indeed online presence and a student's digital professionalization is of increasing concern in social work (Taylor, 2017). Whether it be in the office, in a service user's home, in supervision or within a virtual environment, these all become places and spaces where assessment can occur. It is essential to highlight that these are also learning spaces and the student who is empowered to disclose and self reflects during supervision, ought not to be disadvantaged for doing so. 


\section{The way assessment takes place}

The findings from this research suggest that students initially struggle to recognise the range of ways that the practice educator may have assessed them other than through direct observation of their practice and reading written work. Thompson (2006) rightly points out the assessment of students in the workplace 'must be based on evidence, and the wider the range and scope of evidence, the better' (Thompson, 2006:112-113). The ways that assessment typically occurs is through performance evidence (what is seen) and capability evidence (what is implied through behaviour, written work and conversation) (Barnett, 1994; Eraut, 1994). It is good practice to draw upon a wide range of ways to inform assessment including, but not limited to, watching a student, listening carefully to the words they use (or don't use), posture during a meeting, obtaining feedback from others, role-play and conduct during supervision. These different sources can be 'triangulated' to enable the practice educator to form judgement about a student's confidence, capability and competence (Mathews et al., 2014:103). The diverse ways in which practice educators assess students appear to be 'hidden' or at least less clearly defined for students. There are opportunities for universities and practice educators to discuss with students the different ways that knowledge, skills and values are assessed.

\section{What is assessed?}

The Professional Capabilities Framework (PCF) (BASW, 2016) currently employed in England, has nine interdependent domains which are intended to represent competence and capability for social work practice (TCSW, 2012a). To assess that a student is fit in practise, the practice educator ought to consider the 
student's behaviour, values, attributes, resilience, progress, ability to undertake various social work roles, time management, response to feedback, approach to learning, emotional competence, motivation, critical thinking, ability to manage a case load, use of nonverbal communication, knowledge, skills and the list continues.

Engaging in the discussion about what may be taken into consideration when forming judgements about a student's fitness to become a social worker offers the opportunity to explore the ongoing debate about social work practice, values and professional expectations (Higgins, 2017:43). Such conversations have the potential to help students develop their social worker identity and their understanding of what constitutes competence for social work practice. What is assessed is more than what the practice educator sees when they undertake direct observations or what they read in the student's written work. The assessment of capability is a holistic assessment which may include anything and everything: spoken, implied or performed. Everything the student says and does, and possibly even what they do not say or do not do may all count towards the assessment of capability and competence for the profession. That is because 'whole [social work practice] can only be seen in light of the parts and the parts can only be judged in terms of the whole' (Maclean \& Caffrey, 2014:81).

\section{The Transparency of Assessment in Practice Education; The TAPE model}

The Transparency of Assessment in Practice Education (TAPE) model is presented here to help draw attention to the six Ws of assessment as outlined above (who, when, why, where, way and what). The TAPE model is a visual tool, developed by the author, that may be drawn upon by the practice learning community to illuminate those aspects that comprise the assessment of the student on placement. The model can be used to engage students, tutors and practice 
educators in dialogue before and during placements to stimulate discussion about assessment so that all parties are clear about the nature and form of assessment.

Working around the segments of the diagram offers the opportunity for both tutor and practice educator to ask the student about their experiences of being assessed so that any concerns and issues can be addressed. Using the TAPE model throughout the placement serves as a reminder to all parties that not only is assessment continuous but it is best understood as an explicit, if evolving process, which ultimately will work towards a final assessment that is more reliable, sufficient, fair, clear and valid (Furness \& Gilligan, 2004) and transparent.

Drawing attention to assessment in this way has the potential to avoid mistrust and ambiguity and help in the development of more trusting assessment relationships between student and practice educator. It is anticipated that by making assessment clearer more students will move away from experiencing assessment as punitive and oppressive. Discussion can develop 'awareness of and acknowledging issues of power ... creating open and honest relationships' (Parker, 2010b:996). The student can be empowered to speak about their experiences of being assessed and invited to exert some forms of control within elements of assessment such as arranging the direct observation of their practice. The TAPE model offers the opportunity to acknowledge the inherent power dynamics at play through discussing the roles played by all stakeholders in assessment and in the gatekeeping for the profession. 
What: Everything including behaviour, spoken word, writing, nonverbal responses, relationships, emotional competence, approach to learning, Who: Everyone including service motivation, time keeping and resilience.

Way: Performance evidence (what is seen) and capability evidence (was is implied through behaviour, written work and conversation). Includes formal and informal observation, feedback, supervision and role-play.

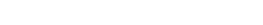
users, carers, practice educator, practice supervisor, community members and other professionals

Where: Every place including service users homes, community settings, online social media, office, social spaces and supervision.
Why: Formative to shape learning opportunities, support and development. Summative end point assessment.
When: All the time. From the very first contact and continuously throughout the learning period.

The TAPE model also has the potential to become a medium for maximising support and the learning potential of students during practice learning placements through the articulation of needs and expectations. However, it is important to acknowledge that making the assessment process more transparent has the potential to increase anxiety in students. Some of the participants in this study suggested that the observation of their practice caused them to feel anxious because they were aware they were being assessed. Students who were unaware that the person they had been working alongside may contribute to the assessment, appeared to experience no negative emotions in response to such situations. It is therefore reasonable to suggest that if we make students more aware that everything they say and do on placement may be assessed and that everyone they meet may potentially contribute to the assessment, there is a 
possibility that they may become more anxious and nervous which could be detrimental to learning:

People do not learn when they are fearful, so it is therefore essential that you are able to create a culture of learning and model practice which shows how mistakes can be learnt from and feedback is helpful, in order to enable the student to take a similarly positive approach to their development. (Nicholas \& Kerr, 2015:40)

Thompson (2006) offer a learning continuum with total ease and complacency at one end and the other is characterised by panic, loss of control and feeling overwhelmed. He advises 'that each of the two extremes minimises learning' but learning does 'involve a degree of discomfort, as it entails' readjustment (Thompson, 2006:102). Occupying the middle ground on the continuum is the most conducive to learning because practice educator challenges and tests the student but they experiences this a being safe and supportive.

Lefevre concludes, as does this article, that training for practice educators ought to more explicitly consider the development of supportive and nurturing environments which is characterised by a 'warm, supportive, empowering relationship' (Lefevre, 2005:577). During their training, practice educators could be introduced to the TAPE model and supported in learning to use it to construct and offer supportive assessable learning opportunities to students.

\section{Limitations and credibility}

This study took place at one university at one point in time which potentially impacts generalizability to other institutions and other contexts. Although the sample of eight participants is conducive for phenomenological investigation it is recognised that other studies at other institutions and in other countries, and with a larger sample may further develop insights into the phenomenon of assessment. The participants were all volunteers and therefore there may be a possibility of 
bias due to those who chose to take part having particular interest or experiences they wished to share. The TAPE model has been outlined here as a suggested tool and it would be advantageous to conduct an evaluation of how students, tutors and practice educators perceive its value in practice.

\section{Conclusion}

This study of the perspectives of final year social work students revealed their lack of appreciation of the complexity of assessment during practice learning placements. Students appeared to recognise they were being assessed through their written work and during formal observations of their practice but had limited insight into capability assessments and the range of stakeholders consulted by the practice educator to form a judgement about fitness to practise. The picture conveyed by the students suggested that not all of them routinely received constructive feedback to enhance and structure their learning and development: some had to wait to receive the final report to know how well they had done on placement. Formative assessment should be shared with students throughout the placement period to inform and shape learning and development. Students cannot be expected to improve without an understanding of whether their current practice has reached the required standard nor can they develop confidence in their skills and performance if they do not receive positive reinforcement.

The narratives from the participants in this study resonate with the findings of Lefevre (2005) in relation to the importance of the relationship between the student and the practice educator. The TAPE model has been developed for those within practice education to ensure transparency in assessment and it is anticipated that it may also help develop the professional relationship between the assessor and the assessed. Discussing how assessment is constructed will reduce ambiguity and avoid issues of mistrust. The student can also be 
empowered to take more control and participate in the arrangements for learning and assessment. Although the model is presented here to be used in social work practice education it could also be used for other any assessment relationships in the workplace or classroom.

There is opportunity to include The TAPE model in the training of practice educators and when preparing students for placement. The TAPE model encourages all stakeholders to be explicit about the elements that comprise assessment; who is involved, why assessment takes place, when assessment occurs, where assessment happens, the way in which assessment occurs and what is taken into consideration when making judgements about capability and competence.

\section{References}

Baird, S. L. (2016). Conceptualizing anxiety among social work students: implications for social work education. Social Work Education, 35(6), 719-732. doi:10.1080/02615479.2016.1184639

Barnett, R. (1994). The limits of competence : knowledge, higher education and society. Buckingham: Open University Press.

BASW. (2016). Professional Capabilities Framework. https://www.basw.co.uk/pcf/: British Association of Social Workers.

Beverley, A., \& Worsley, A. (2007). Learning and teaching in social work practice. Basingstoke: Palgrave Macmillan.

Biggs, J., \& Tang, C. (2007). Teaching for Quality Learning at University : What the Student Does (3rd Edition). Buckingham: Open University Press.

Bogo, M., Regehr, C., Hughes, J., Power, R., \& Gioberman, J. (2002). Evaluating A Measure Of Student Field Performance In Direct Service: Testing Reliability And Validity Of Explicit Criteria. Journal of Social Work Education, 38(3), 385-401.

Cleak, H., Hawkins, L., Williams, J., \& Laughton, J. (2015). Creating a Standardised Teaching and Learning Framework for Social Work Field Placements. Australian Social Work, 68(1), 49-64. doi:10.1080/0312407X.2014.932401

Costley, C., Elliott, G., \& Gibbs, P. (2010). Doing Work Based Research: Approaches to Enquiry for Insider. London Sage.

Creswell, J. W. (1998). Qualitative inquiry and research design : choosing among five traditions. London: Sage.

Dahlberg, K. (2006). The essence of essences--The search for meaning structures in phenomenological analysis of lifeworld phenomena. International Journal of Qualitative Studies on Health and Well-being, 1(1), 11-19.

Doel, M. (2010). Social Work Placements. A Traveller's Guide. Abingdon: Routledge.

Eraut, M. (1994). Developing professional knowledge and competence London: Falmer Press.

Field, P., Littler, L., \& Jasper, C. (2014). Practice Education in Social Work : Achieving Professional Standards. St Albans: Critical Publishing. 
Finch, J. (2009). Can't Fail, Won't Fail - Why Practice Assessors Find it Difficult to Fail Social Work Students. A Qualitative Study of Practice Assessors' Experiences of Assessing Marginal or Failing Social Work Students. Professional Doctorate in Social Work Thesis. University of Sussex.

Finch, J. (2017). Supporting struggling students on placement. A practical guide. Bristol: Policy Press. Finch, J., \& Parker, J. (2013). Editorial Special Issue 'Failing students'. The Journal of Practice Teaching and Learning, Volume 11, Number 3 3-7.

Finch, J., \& Taylor, I. (2012). Failure to Fail? Practice Educators' Emotional Experiences of Assessing Failing Social Work Students. Social Work Education: The International Journal, pp. 1-15.

Furness, S., \& Gilligan, P. (2004). Fit for purpose: issues from practice placements, practice teaching and the assessment of students' practice. Social Work Education, 23(4), 465-479.

Giorgi, A., \& Giorgi, B. (2008). Phenomenology. In J. A. Smith (Ed.), Qualitative Psychology. A practical Guide to Research Methods (2nd ed.). London: Sage.

HCPC. (2012). Standards of proficiency. Social work in England. London: Health and Care Professions Council.

Higgins, M. (2017). Conflicting and Competing Roles and Expectations: the Conundrum of Failing Social Work Students on Placements. Czech \& Slovak Social Work, 17(1), 38-46.

Hockey, J. (1993). Research methods -- researching peers and familiar settings. Research Papers in Education, 8(2), 199.

Kanno, H., \& Koeske, G. F. (2010). MSW Students' Satisfaction with Their Field Placement: The Role of Preparedness and Supervision Quality. Journal of Social Work Education, 46(1), 23-38.

Ketner, M., VanCleave, D., \& Cooper-Bolinskey, D. (2017). The Meaning and Value of Supervision in Social Work Field Education. Field Educator, 7.2 (Fall 2017), 1-18.

Lefevre, M. (2005). Facilitating Practice Learning and Assessment: The Influence of Relationship. Social Work Education, 24(5), 565-583. doi:10.1080/02615470500132806

Lester, S. (1999). An introduction to phenomenological research. https://www.rgs.org/NR/rdonlyres/F50603E0-41AF-4B15-9C84BA7E4DE8CB4F/0/Seaweedphenomenologyresearch.pdf Accessed 6-3-17.

Lodico, M. G., Spaulding, D. T., \& Voegtle, K. H. (2010). Methods in educational research : from theory to practice San Francisco: Jossey-Bass. 2nd. ed.

Maclean, S., \& Caffrey, B. (2014). Developing a Practice Learning Curriculum. A guide for practice educators. Staffs: Kirwin Maclean Associates Ltd.

Mathews, I., Simpson, D., \& Crawford, K. (2014). Your Social Work Practice Placement. London: Sage.

Miller, J., \& Koerin, B. B. (2001). Gatekeeping in the Practicum: What Field Instructors Need to Know. Clinical Supervisor, 20(2), 1.

Nicholas, W. S., \& Kerr, J. (2015). Practice Educating Social Work Students. Supporting Qualifying Students on Their Placements. Maidenhead: Open University Press.

O.E.D. (2015). Oxford English Dictionary. http://www.oed.com/: Oxford University Press.

Parker, J. (2004). Effective Practice Learning in Social Work. Exeter: Learning Matters.

Parker, J. (2010a). Effective Practice Learning in Social Work (2nd ed.). Exeter: Learning Matters.

Parker, J. (2010b). When Things Go Wrong! Placement Disruption and Termination: Power and Student Perspectives. British Journal of Social Work, 40(3), 983-999. doi:10.1093/bjsw/bcn149

Pringle, J., Drummond, J., McLafferty, E., \& Hendry, C. (2011). Interpretative phenomenological analysis: a discussion and critique. Nurse Researcher, 18(3), 20-24.

Smith, J. A. (1996). Beyond the divide between cognition and discourse: using interpretative phenomenological analysis in health psychology. Psychology \& Health, 11(2), 261-271.

Smith, J. A., Jarman, M., \& Osborn, M. (1999). Doing interpretative phenomenological analysis. In M. Murray \& K. Chamberlain (Eds.), Qualitative health psychology : theories and methods: London: Sage

Smith, J. A., \& Osborn, M. (2008). Interpretative Phenomenological Analysis. In J. A. Smith (Ed.), 
Qualitative psychology : a practical guide to research methods London: Sage, 2nd ed.

Stone, C. (2014a). Competence units or holistic assessment: The Language may be different but the challenges continue. The Journal of Practice Teaching and Learning, 13 (1), 44-56.

Stone, C. (2014b). An exploration of how Practice Educators use competency frameworks to assess social work students in practice learning settings Doctoral Thesis. University of Central Lancashire.

Stone, C. (2015). Developing method to meet the needs of the research. Journal of International Doctoral Research, 4. number 1, 10-31.

Stone, C. (2016). The role of practice educators in initial and post qualifying social worker education. Social Work Education, 35(6), 706-718.

SWRB. (2010a). Building a Safe and Confident Future: One year on. Detailed proposals from the Social Work Reform Board. www.education.gov/swrb: Crown Copyright.

SWRB. (2010b). Practice Educator Professional Standards for Social Work. Retrieved from http://www.education.gov.uk/swrb/education.shtml:

Taylor, A. (2017). Social work and digitalisation: bridging the knowledge gaps. Social Work Education, 36(8), 869-879. doi:10.1080/02615479.2017.1361924

TCSW. (2012a). Assessing Practice Using the Professional Capabilities Framework. Retrieved from http://www.tcsw.org.uk/uploadedFiles/TheCollege/Resources/Assessing\%20practice\%20usi ng\%20the\%20PCF\%20guidance\%200ct12(3).pdf:

TCSW. (2012b). Practice Educator Professional Standards and Guidance. Retrieved from http://search.collegeofsocialwork.org/search/search.cgi?collection=sciecosw\&query=PRACTICE\%20EDUCATORS:

TCSW. (2013). Practice learning guidance. Placement criteria (edref9). Retrieved from http://www.collegeofsocialwork.org/uploadedFiles/TheCollege/ CollegeLibrary/Reform res ources/PlacementCriteria(edref9).pdf:

Thompson, N. (2006). Promoting Workplace Learning. Bristol: The Policy Press.

Vandermause, R. K., \& Fleming, S. E. (2011). Philosophical Hermeneutic Interviewing. International Journal of Qualitative Methods, 10(4), 367-377.

Williams, S., \& Rutter, L. (2010). The practice educator's handbook Exeter : Learning Matters.

Zeira, A., \& Schiff, M. (2014). Field Education: A Comparison of Students' and Novice Social Workers' Perspectives. British Journal of Social Work, 44(7), 1950-1966. 